\title{
Analysis and Validation of Laser Spot Weld-Induced Distortion
}

\author{
G.A. Knorovsky, M.P. Kanouff ${ }^{+}$, D.O. MacCallum \& P.W. Fuerschbach \\ Sandia National Laboratories, Albuquerque, $\mathrm{NM}$ and Livermore, $\mathrm{CA}^{+}$
}

\begin{abstract}
$\underline{\text { Abstract }}$
Laser spot welding is an ideal process for joining small parts with tight tolerances on weld size, location, and distortion, particularly those with near-by heat sensitive features. It is also key to understanding the overlapping laser spot seam welding process. Rather than attempting to simulate the laser beam-to-part coupling (particularly if a keyhole occurs), it was measured by calorimetry. This data was then used to calculate the thermal and structural response of a laser spot welded SS304 disk using the finite element method. Five combinations of process parameter values were studied. Calculations were compared to experimental data for temperature and distortion profiles measured by thermocouples and surface profiling. Results are discussed in terms of experimental and modeling factors. We then suggest appropriate parameters for laser spot welding.
\end{abstract}

\section{Introduction}

Welding creates a highly non-uniform temperature field, resulting in local plastic strain, residual stress and concerns about cracking and distortion. Thermally-induced stress is particularly important when closure welding small hermetic packages with glassto-metal seals. Moreover, closure welding comes at the end of the manufacturing process, so scrap due to welding-induced defects is costly. Laser welding is known to produce low heat input, low distortion, hence it is often specified for such welds. Given industry's need for miniature high reliability components, understanding laser welding is critical.

Descriptions of numerical models of welding can be found in the literature spanning the last four decades and more. Some recent contributions are listed. Goldak et.al. (1991) give a comprehensive discussion of the mechanics of material response to welding and its computation. Calculations of gas-metal arc welding of steel (GMAW), including the effect of metal deposition, have been published by Karlsson et.al. (1990) and Tekriwal et.al. (1991). Ortega et.al. (1992) calculated the response of SS304 to single spot GMA welds. Calculations have been made for multipass gas-tungsten arc (GTA) welds by Root et.al. (1992), Dong et.al. (1998) and Ortega et.al. (1998). Models for laser welding have been described by Tsai et.al. (1998). These calculations show that material near the weld is heated to softening temperature $\left(>400\right.$ to $600^{\circ} \mathrm{C}$ for steel). It then plastically deforms due to a combination of thermal expansion and constraint imposed by the relatively cold and strong surroundings. When this material subsequently cools, the surrounding material now constrains it from contracting, leaving a state of residual tension. The residual stress level is often near the yield stress of the base metal.

Welding heat is applied to the weldment surface, resulting in the formation of a molten zone. Convection heat transfer by fluid motion in the melt dominates conduction. The models listed used a simplified approach where melt fluid motion was neglected and only the conduction equation was solved for energy transport. Often, an enhanced liquid thermal conductivity accounted for convective heat transfer, e.g. Karlsson et.al. (1990).

Our calculations and measurements of the weld size, thermal response and part distortion were carried out for the configuration shown in Figure 1, where a single laser 


\section{DISCLAIMER}

This report was prepared as an account of work sponsored by an agency of the United States Government. Neither the United States Government nor any agency thereof, nor any of their employees, make any warranty, express or implied, or assumes any legal liability or responsibility for the accuracy, completeness, or usefuiness of any information, apparatus, product, or process disclosed, or represents that its use would not infringe privately owned rights. Reference herein to any specific commercial product, process, or service by trade name, trademark, manufacturer, or otherwise does not necessarily constitute or imply its endorsement, recommendation, or favoring by the United States Government or any agency thereof. The views and opinions of authors expressed herein do not necessarily state or reflect those of the United States Government or any agency thereof. 


\section{DISCLAIMER}

Portions of this document may be illegible in electronic image products. Images are produced from the best available original document. 
spot weld was made in the center of a $25.4 \mathrm{~mm}$ diameter, $1.2 \mathrm{~mm}$ thick, SS304 disk. Energy absorption was measured using a Seebeck envelope calorimeter.
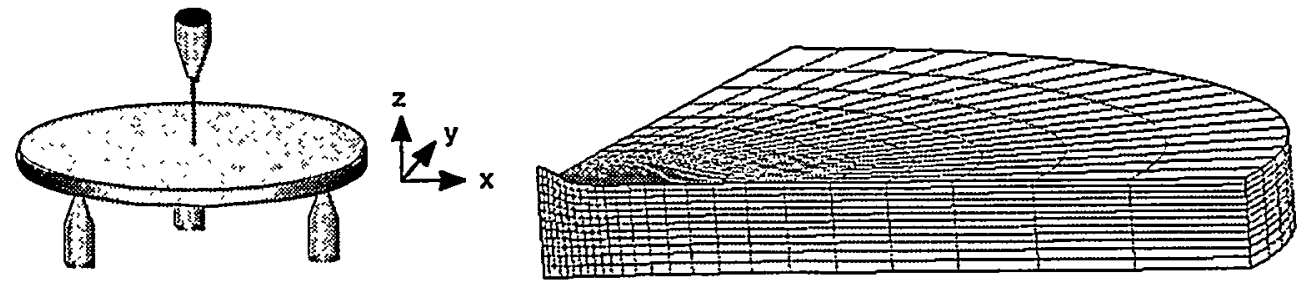

Figure 1: Geometry and mesh used to study laser spot welds. The mesh shows the distorted shape of the disk after welding (distortions magnified by $10 \mathrm{X}$ ).

\section{Experimental Procedures}

The heat absorbed was found by measuring and integrating the flux through the calorimeter walls as the sample cooled to ambient. A large number of separated spot welds in a raster pattern were made on $51 \times 102 \times 6.35 \mathrm{~mm}$ thick SS304 samples placed in the calorimeter. While non-overlapping, the spot spacing may have allowed some preheating, particularly at scan turn-arounds. After completing the scan $(<40 \mathrm{~s})$, the calorimeter was closed, and the flux vs time measurement made and then integrated on a digital oscilloscope. The energy was divided by the number of spots, giving an average. The calorimetry and temperature/distortion welds were made on the same material lot but with different lasers, because of availability. To ensure equivalence, pulse length settings were identical and irradiances matched to $<12 \%$ (ususally $<5 \%$ ). Weld process parameter values are shown in Table 1 . The laser pulse was nominally a square wave.

Table 1. Weld process parameter values used in the experiments and calculations

\begin{tabular}{cccc}
\hline case & $\begin{array}{c}\text { Pulse energy } \\
\Delta \mathrm{E}-\mathrm{J}\end{array}$ & $\begin{array}{c}\text { Pulse duration } \\
\delta \mathrm{t}-\mathrm{ms}\end{array}$ & $\begin{array}{c}\text { Spot diameter } \\
\mathrm{mm}\end{array}$ \\
\hline 1 & 2.00 & 7 & 0.41 \\
2 & 3.33 & 7 & 0.46 \\
3 & 5.66 & 7 & 0.46 \\
4 & 1.50 & 2.2 & 0.41 \\
5 & 2.25 & 2.2 & 0.41 \\
\hline
\end{tabular}

The disks were supported by three sharp contact points (see Figure 1) to minimize conductive heat losses and fixture constraints. Disks were lapped to $\sim 0.3 \mu \mathrm{m}$ finish and flatness of $+/-2 \mu \mathrm{m}$, to give a reproducible starting condition (calorimetry samples were as-wrought, but the disks were EDM'd from $6.35 \mathrm{~mm}$ plate and needed cleaning). Spot welds was made using a single laser pulse with a specified spot diameter, pulse time and energy. The laser pulsed at a specified frequency, but a shutter blocked all but one pulse. To minimize convective loss no shielding gas was used. Temperatures were measured with $0.12 \mathrm{~mm}$ diameter type $\mathrm{K}$ thermocouples (TC's) attached at four locations, two on top and two on the bottom. All four were attached on a common diametral plane. Because the TC's were unshielded, electrical noise from the laser system was present. After welding, a profilometer was used to measure the shape of the disk along two diametral traces on the upper surface, one parallel and one perpendicular to the line of TC's. The profile was then subtracted from a composite profile derived from five unwelded samples to obtain the part distortion. Finally, metallographic sections were made to obtain the weld sizes and shapes and to verify TC locations. 


\section{Finite Element Model}

The finite element method was used to calculate the transient response of the disk to a single laser pulse. The calculations were made using parallel processing to reduce run times and permit a more thorough study of the problem. Thermal response calculations were done first, and used as input data for the mechanical response calculations. The same finite element mesh was used for both calculations (see Figure 1).

The thermal response was governed by heat conduction, i.e. the effects of fluid flow and keyhole formation in the weld pool were not treated explicitly in the calculations. However, we recognized that keyhole formation has a large effect on heat transfer and the shape of the weld pool. We accounted for this by using an orthotropic thermal conductivity where the conductivity normal to the surface of the disk was enhanced for super-liquidus temperatures. For sub-liquidus values an isotropic temperature-dependent conductivity was used. The temperature-dependent properties used are shown in Figure 2. A constant density of $7920 \mathrm{Kg} / \mathrm{m}^{3}$ was employed.

The laser pulse was modeled by a flux boundary condition on the disk surface. The heat flux was Gaussian, with a radius $\left(=1 / \mathrm{e}^{3}\right)$ of $0.5 \mathrm{~mm}$. All other disk surfaces were adiabatic, as losses were accounted for in the measured efficiency. Thermal calculations used COYOTE (Gartling, et.al., 1999).

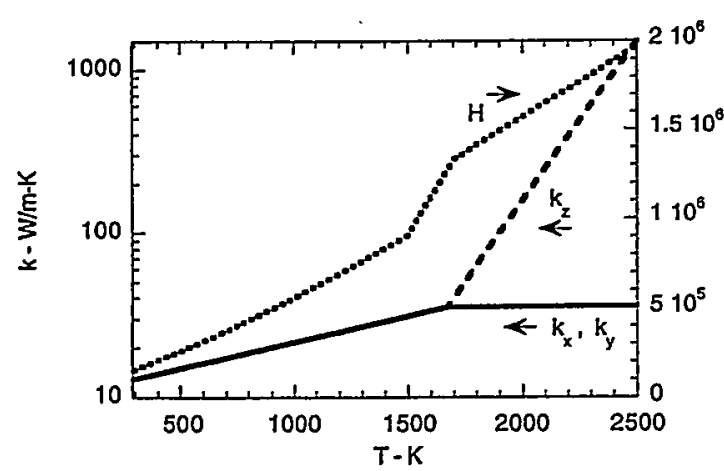

Figure 2: Enthalpy $(\mathrm{H})$ and thermal conductivity ( $k$, subscript is direction) vs temperature.

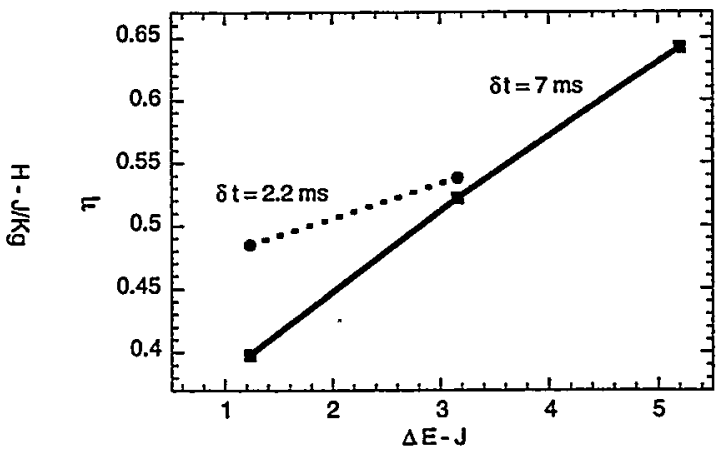

Figure 3: Laser absorption efficiency $\eta$ vs pulse energy $\Delta E$, and pulse length $\delta$ t.

Mechanical response calculations used a BCJ elastic-plastic material model with temperature- and strain rate-dependent yield strength, hardening and recovery (Bammann, et. al., 1995) which accounts for load path history effects with internal state variables. Modifications to the model included capping the temperature at the liquidus value, preventing negative hardening, and setting deviatoric stresses and internal state variables to zero at the liquidus. Model parameters specific to SS304 were experimentally determined, by Ortega et.al. (1998) who analyzed a multipass GTA weld

Both thermal and mechanical calculations were three-dimensional (3D), due to use of a 3D-only mechanical code: JAS3D (Blanford, 1998). Using 3D codes anticipated the next study phase: overlapping spot welds. The finite element mesh used spanned a quarter of the disk. Symmetry boundary conditions were used on the two straight sides. The mesh contained 39725 nodes, and 36480 eight-node brick elements. Both COYOTE and JAS3D use conjugate gradient-based solution methods. At least five iterations were required per time step in the mechanical calculations to reduce temporal oscillations. 1 and $2.5 \mu$ s time steps were used in the thermal and mechanical calculations, respectively. 


\section{Results}

Calorimetric measurements of the laser energy absorption efficiency $\eta$ are shown in Figure 3. $\eta$ is defined as the ratio of the energy absorbed to the energy in the laser pulse. The difference between the energy absorbed and the pulse energy is due to losses (reflection from the metal surface, evaporation, radiation and convection). The results show a nearly linear relationship between $\eta$ and $\Delta \mathrm{E}$. The increase in $\eta$ with $\Delta \mathrm{E}$ may be due to the formation of a keyhole, resulting in higher absorption of the laser via multiple reflections in the vapor cavity. The results for $2.2 \mathrm{~ms}$ also increase slightly over the small range of $\Delta \mathrm{E}$ measured; however, $\eta=0.48$ was assumed in the $2.2 \mathrm{~ms}$ pulse calculations.

(a)

The experimental and calculated weld shapes are shown in Figure 4.

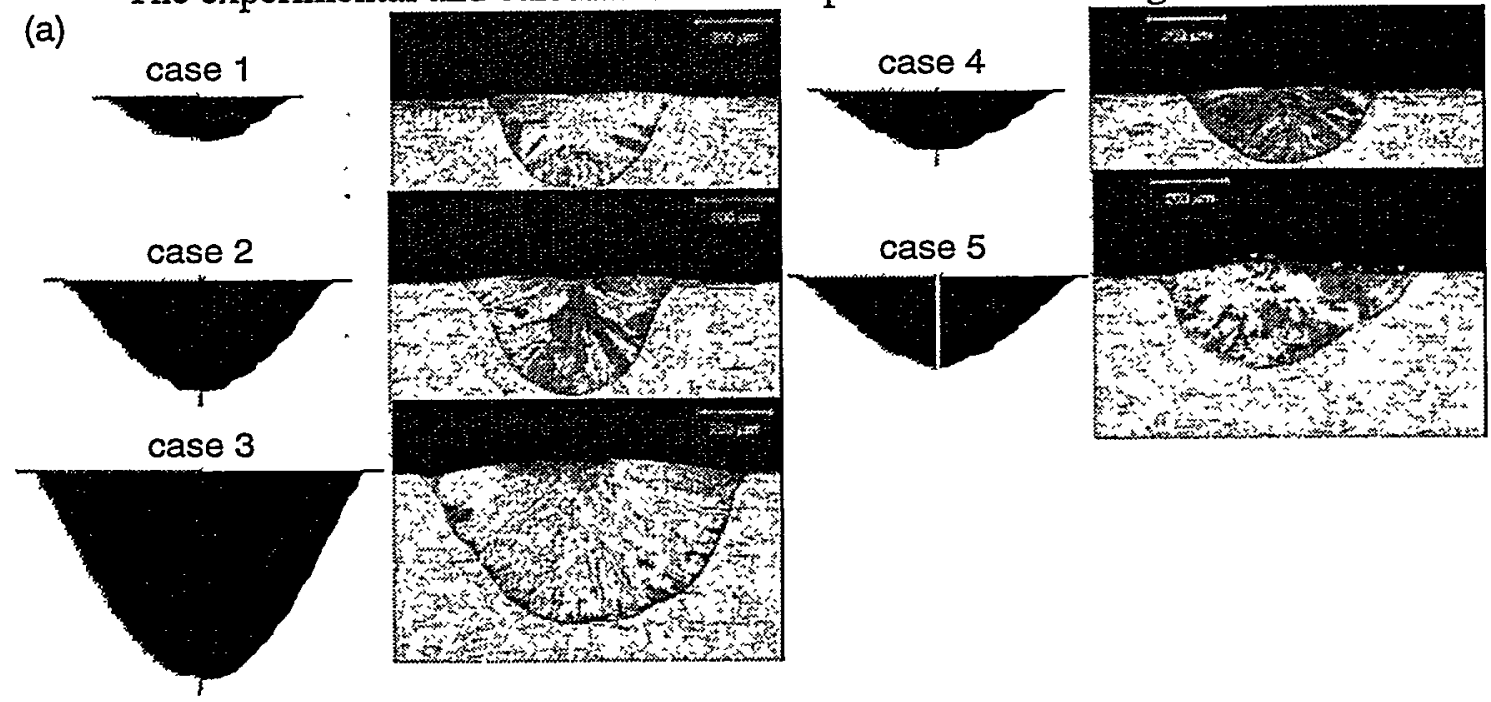

(b)

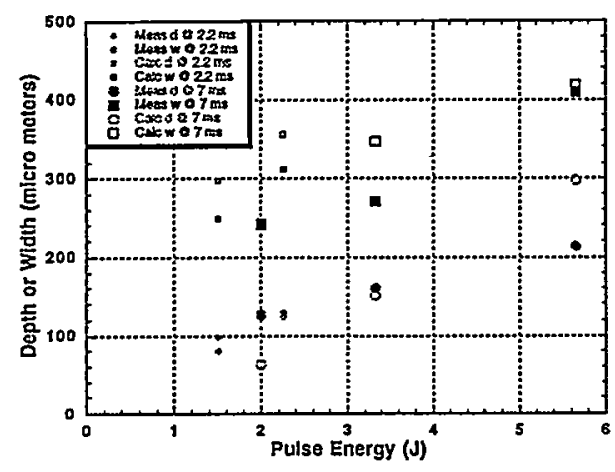

Figure 4a: Weld shapes obtained from experiment and calculation. 4b: Measured and calculated weld depth and width vs pulse energy input.

Some disagreement may be due to the inherent variability of pulsed laser welds. For example, in the calorimetry samples, metallographic sections showed a spot-to-spot depth variation of $4-15 \%$ and width variation of $2-7 \%$ for a given schedule. On the whole, calculated and measured values are in fair agreement, and it appears that for a given pulse energy, while width is not sensitive to pulse length, depth increases for shorter pulses.

Figures 5-8 show the calculated and measured temperatures vs time at points on the top and bottom surfaces. The TC's were placed close to the weld target location, but far enough away to survive the weld. Their actual locations relative to aim point were 

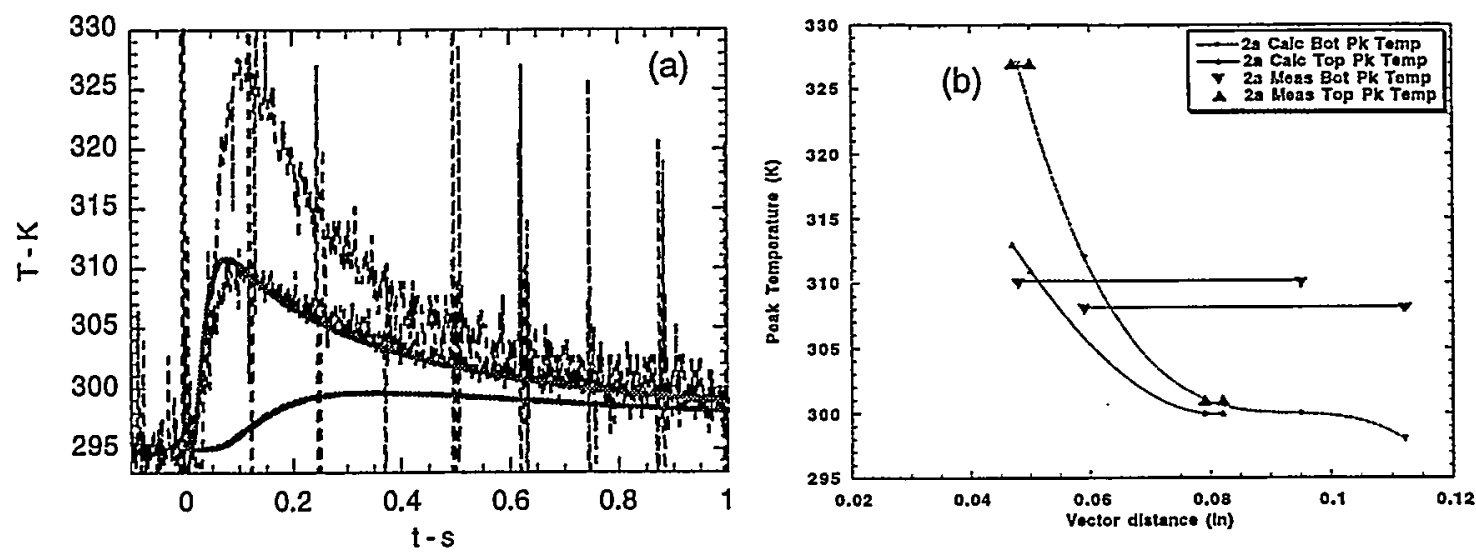

Figure 5a: Measured (noisy) and calculated (smooth) temperatures vs time on top and bottom surfaces for case 1: $2 \mathrm{~J}, 7 \mathrm{~ms}$. TC-to-weld-center distance: $1.1 \mathrm{~mm}$ (top), $1.9 \mathrm{~mm}$ (bottom). 5b: Calculated and measured peak temperatures vs distance.
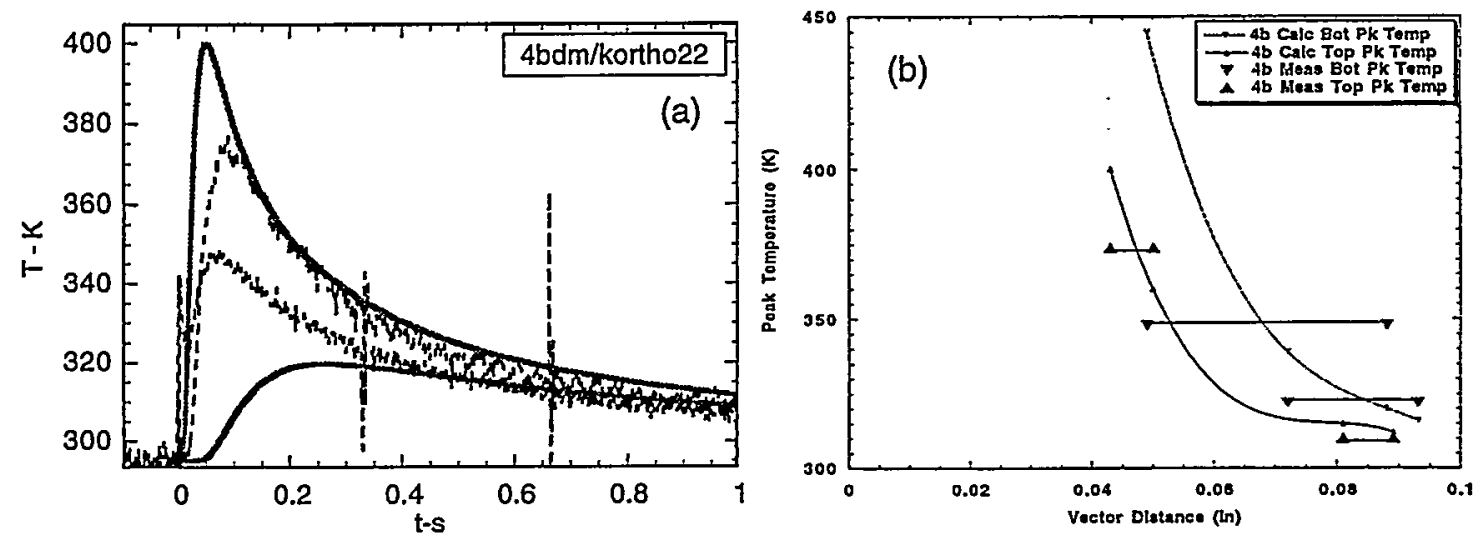

Figure 6a and 6b: Same as Figure 5 for case 3: 5.7J, 7ms. TC-to-weld-center distance: $1.1 \mathrm{~mm}$ (top), $1.9 \mathrm{~mm}$ (bottom).
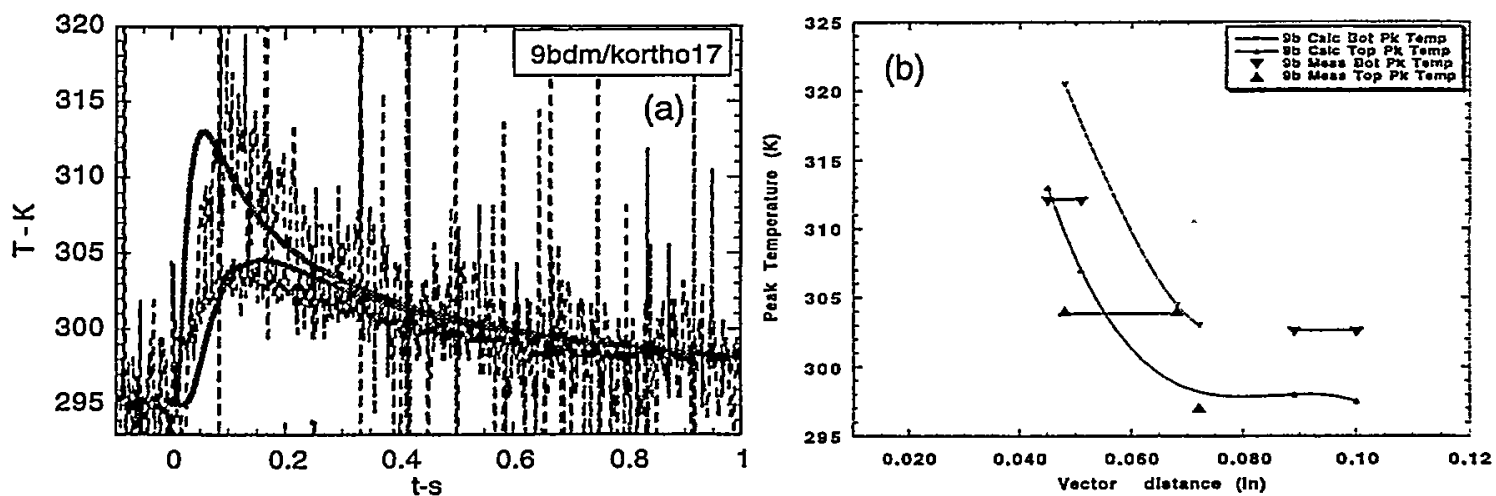

Figure 7a and 7b Same as Figure 5 for case 4: 1.5J, 2.2ms. TC-to-weld-center distance: $1.1 \mathrm{~mm}$ (top), $1.2 \mathrm{~mm}$ (bottom).

difficult to precisely control, so post-weld measurements were made. As noted already, the TC data was noisy. Although only one laser pulse was incident on the disk, the laser was pulsed at a specified frequency. The electrical noise signature from these pulses can be seen in the TC data as spikes occurring at the laser pulse rate. The spikes identified the beginning of the laser pulse and allowed synchronization of the calculations and 

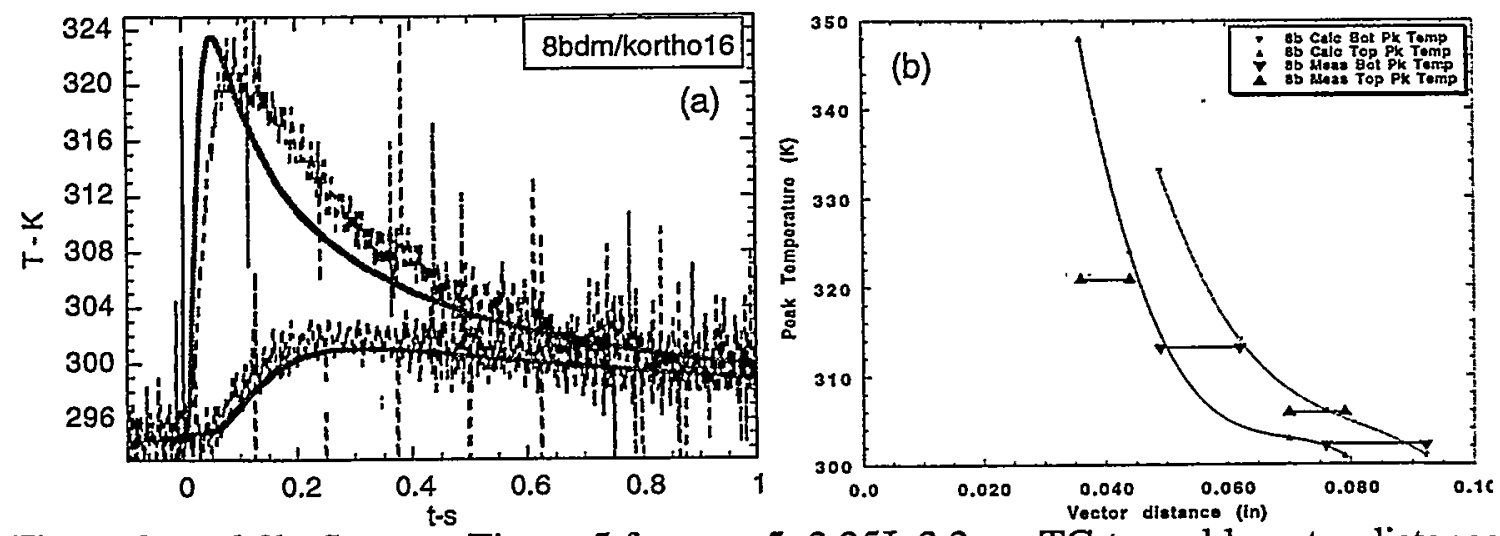

Figure 8a and 8b: Same as Figure 5 for case 5: 2.25J, 2.2ms. TC-to-weld-center distance: $1.1 \mathrm{~mm}$ (top), $2.0 \mathrm{~mm}$ (bottom).

measurements. In a few cases, for TC's on the top surface, an early rise in the signal coincident with the laser pulse is thought due to reflected laser energy directly heating the TC. The nominal distances of the TC's from their respective spot-weld centers ranged from 1-2 mm. Although the TC's were close to the spot welds, the measured temperatures were very small. The comparison between calculated and measured temperatures is good in some cases, poor in others. The poor agreement could be partly due to the difficulty of measuring the distance of a TC from the spot weld, where some judgment was used in estimating the actual TC location and the actual spot weld center. Also shown in Figures 5-8 is the peak temperature vs TC location. TC positional errors were estimated from metallographic sections of the TC's (where available), or from multiple measurements by different people. (Lines joining the calculated points are third order polynomial fits for indication only.) It is notable that the bottom TC's reach a higher peak value than those at equivalent distances on top. We believe this is due to the insulating behavior of the bottom surface where the predominant heat flow is normal to the surface, and 'piles up'. On top, the heat flows parallel to the surface, and no such behavior occurs. It is also noticeable that at a given distance, the peak temperature increases with pulse energy, with no effect of a shorter pulse time. The peak temperatures are reached in a few tenths of a second, which is long compared with the weld pulse. This may not be true in and near the fusion zone.

Figure 1 shows the calculated distorted disk shape for case $2(3.33 \mathrm{~J}, 7 \mathrm{~ms})$ magnified by $10 \mathrm{x}$. The distorted disk is depressed towards the center relative to the edge, with the exception of the fusion zone region, where there is a mound. This mound results from the plastic deformation of the material surrounding the weld. During the laser pulse this material was heated to high temperatures while the material at larger distances from the weld pool remained relatively cool. The lack of expansion in the cooler material results in a constraint on the radial expansion of the hot material close to the weld. This causes the near-weld material to expand plastically (i.e. there is a permanent component to the deformation) in the $z$-direction, giving the central mound. When this material cools, it contracts in both the axial and radial directions. However, due to the permanent component of the axial expansion, the contraction in the radial direction of the near weld material is such that its radial dimension is smaller after the welding operation than it was before the operation resulting in a tensile radial stress and the concave shape in the part as the near weld material attempts to contract in the radial direction and the far weld material constrains this contraction.

The profilometer data for the disk upper surface is shown in Figures 9-12. This 


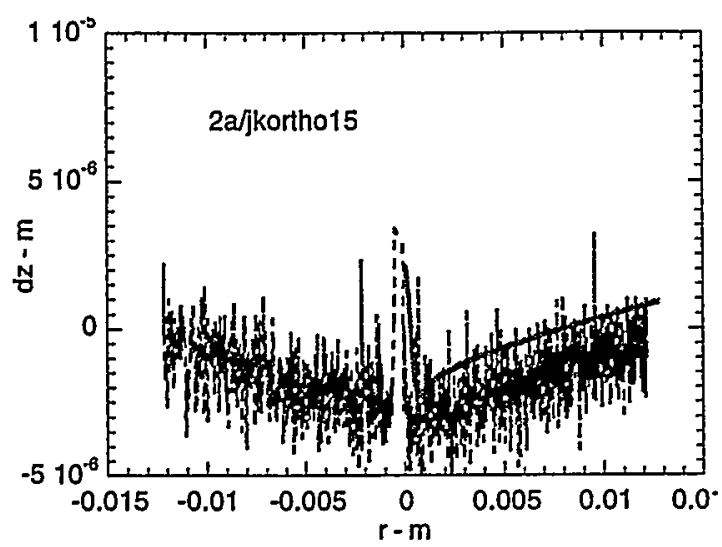

Figure 9: Measured (noisy) and calculated (smooth) distortion along a diameter on the disk top surface. Case 1: 2J, $7 \mathrm{~ms}$.

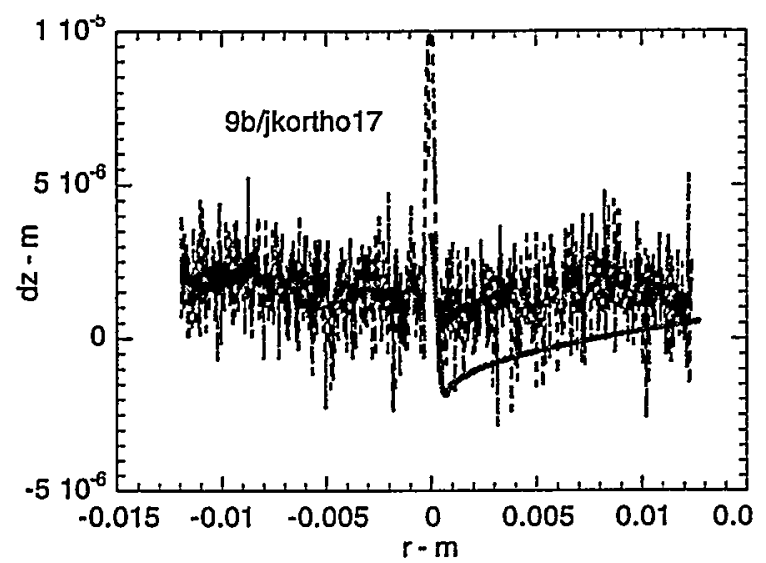

Figure 11: Same as Figure 9 for Case 4: $1.5 \mathrm{~J}, 2.2 \mathrm{~ms}$.

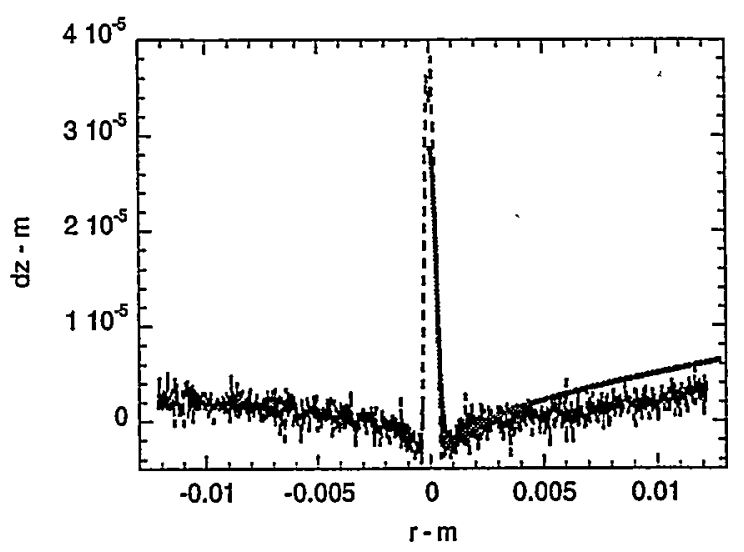

Figure 10: Same as Figure 9 for Case 3: $5.7 \mathrm{~J}, 7 \mathrm{~ms}$.

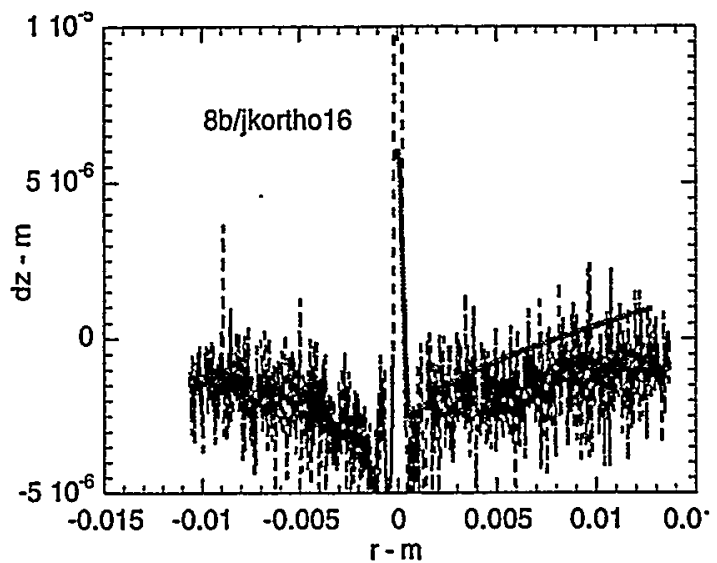

Figure 12: Same as Figure 9 for Case 5 $2.25 \mathrm{~J}, 2.2 \mathrm{~ms}$.

data shows the distortion perpendicular to the plane of the disk (z-direction) along a disk diameter. The very small stylus used for the profile measurements also captured the surface roughness of the disk. For each case the central surface mound of the weld can be seen $($ at $r=0$ ). Beyond the mound the disk is depressed relative to its edge. The calculated results for the distortion of the disks are also shown in Figures 9-12, and are generally in good agreement with the measured results for that portion of the profile outside of the weldment mound. The agreement between calculated and measured results for the weldment mound height ranges from fair to good. From the metallography, it was noted that the small laser spot welds attaching the TC's were in fact not small. In some cases they were comparable to the target weld. Fortunately, their symmetry cancelled out much of their effect. Some simple superposition calculations were made where the distortion calculated for case 3 was multiplied by $1 / 4$ (to simulate a quarter-size TC weld) and then translated and/or inverted (depending if the TC was on the top surface or bottom) then summed to estimate the distortion of the four TC welds. In the diametral plane containing the TC welds, there was an appreciable local distortion hump added; while in the perpendicular diametral plane a more general 'valley' effect was noted $(\sim 4 \mu \mathrm{m})$, as illustrated in Figure 13. Also shown is the superposition of all 5 welds. The estimated effect of the TC welds is similar to the non-flatness after lapping. 

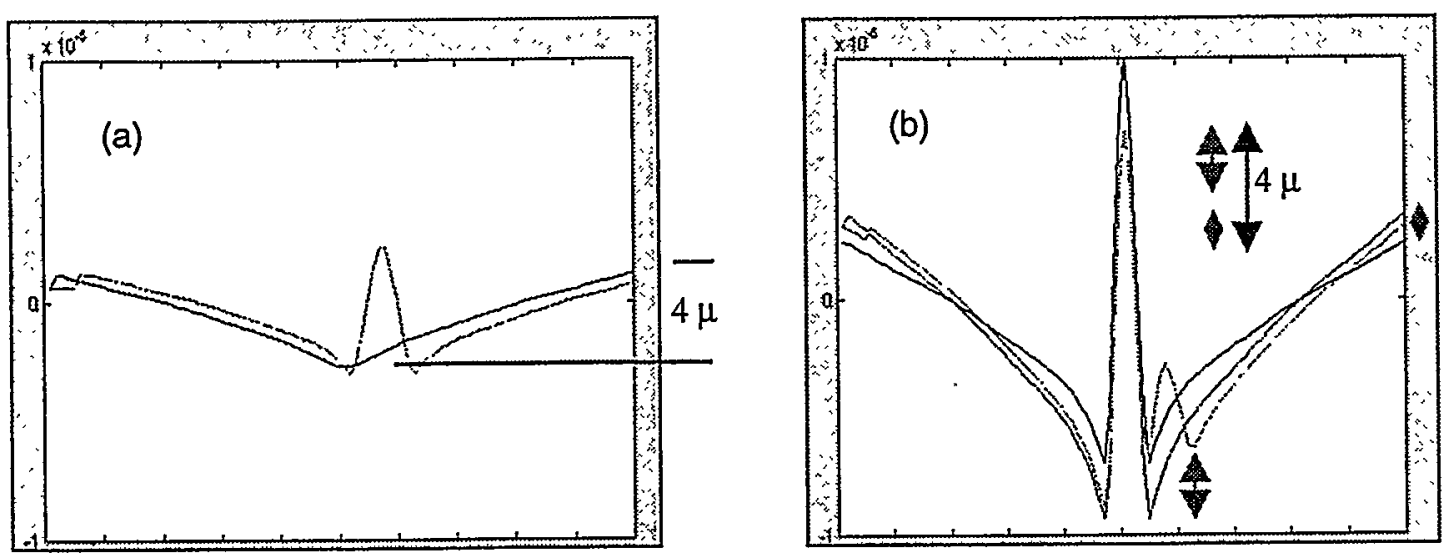

Figure 13a: Parallel and perpendicular results of superposing distortion from quarter-size (of case 3) spot welds. 13b: Superimposed distortions of case 3 weld +4 TC welds.

The agreement between measured and calculated distortion profiles isgood even though the calculated results for the weld shapes were only in fair agreement with the experimental results. This suggests that there is an insensitivity of the distortion to the weld shape. As noted by others (Karlsson et. al. (1990), Tekriwal et. al. (1991)), the mechanical response depends more on the size of the heat-affected zone, i.e. the material heated to above 400 to $600 \mathrm{C}$ for steel. The shape of this zone is only weakly related to the shape of the weld and is mainly dependent on the amount of energy deposited in the metal during the welding process. By plotting the calculated and measured distortion difference from the central valley to the outer diameter, this can be seen in Figure 14. The residual stress state for case 2 (3.33J, $7 \mathrm{~ms}$ ) is shown in Figure 15.

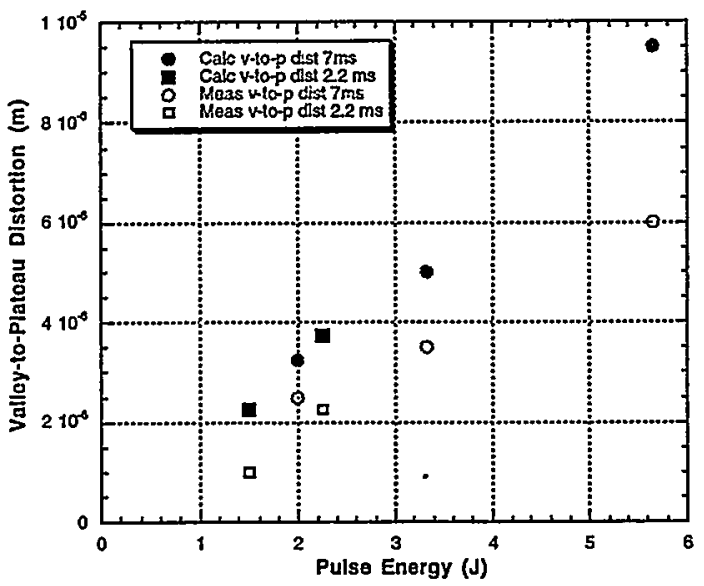

Figure 14: Calculated and measured valley-to-edge distortion difference vs pulse energy.

This figure shows the stress, $\sigma_{x x}$, on a x-z plane through the center of the weld. The stress is in tension in the weldment and surrounding material with a maximum value near 400 $\mathrm{MPa}$. A smaller tensile stress exists at the upper surface of the weldment. The stress is in compression in the lower portion of the disk, with the exception of a small region of material that is in tension on the bottom of the disk beneath the weld. This general stress state is similar to the results of Ortega et. al. (1992) and of Tsai et. al. (1998).

The stress profiles along the z-axis through the center of the weld are shown in Figure 16 for various laser pulse energies (cases 2-5). All the profiles show a large tensile 
stress within the weldment, which decreases towards the top of the weld $(z=0)$, and that changes to compression directly beneath the weld. As the pulse energy increases the location where the stress changes from tension to compression gets deeper. The peak tensile and compressive stresses, however, are somewhat insensitive to the pulse energy.

Based upon the information on depth, width, distortion and residual stress vs pulse energy and length, it appears that the major factor is the pulse energy, with all factors increasing with increased energy (the residual stress peak level is not increased because it is material-limited, but the high tensile stress volume increases). There is a slight tendency to increase spot weld depth by choosing a shorter pulse length at constant energy (this will be limited by excessive spatter when the irradiance becomes too high, however). With shorter pulse lengths the weld bulge will increase.

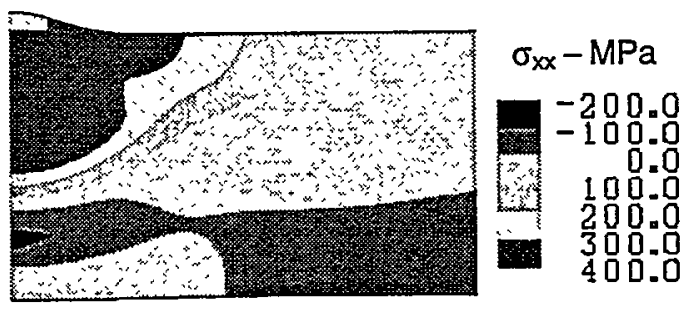

Figure 15: The residual stress state $\left(\sigma_{x x}\right)$ near the weld for case $2: 3.33 \mathrm{~J}, 7 \mathrm{~ms}$.

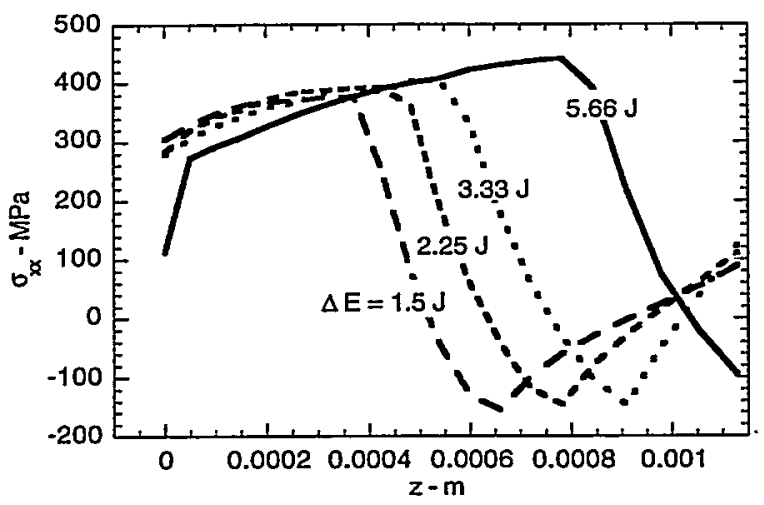

Figure 16: Central axis residual $\sigma_{x x}$ vs depth for various laser pulse energies.

\section{Conclusions and Further Work}

We found calculated and experimental results to be consistent, with areas of further work clearly identified. Bottom surface temperatures were significantly hotter than top surface ones at equivalent vector distance from the aim point. This is attributed to the insulating bottom surface being normal to the predominant heat flow direction rather than parallel, as along the top. Temperatures at $\sim 1 \mathrm{~mm}$ from the target are low, increasing $<100^{\circ} \mathrm{C}$ for a few seconds. Our TC measurements suffered from a lack of positional precision due to the attachment method. Future TC's will use smaller wire, and be attached via percussion welding. TC's will be located closer to the fusion zone to improve signal/noise ratio. The TC welds were large enough to effect the target weld distortion measurements, as did non-flatness of the lapped samples. Future samples will be profiled before and after welding, rather than relying upon lapping to provide flatness. Nevertheless, weld size, shape and distortion calculations and measurements were in 
substantial agreement. Overall peak temperature and distortion values were controlled by the pulse energy, with little effect of pulse length; except the central distortion hump of the fusion zone showed an increased value for shorter pulse lengths at equivalent. In the area of modeling, efforts are being made at calculating the keyhole behavior as controlled by recoil pressure, which should allow its absorption behavior to be assessed; however, the area of beam/plume is still being formulated. Weld schedule choice is constrained since energy is the main parameter to control, with depth, width, distortion and volume of tensile residual stress all increasing with pulse energy, for the range of welds studied in this work. Shorter pulse lengths increase the penetration for a given energy (and the central hump), but will be limited by spatter and loss of material.

\section{Acknowledgments}

We would like to acknowledge a few colleagues: A. Marquez, F. Hooper, J. Lathrop, A. Kilgo, M. Dugger and M. Russell. This work was supported by the U. S. Dept. of Energy under Contract DE-AC04-94AL85000. Sandia is a multiprogram laboratory operated by Sandia Corp., a Lockheed Martin Company, for the U.S. Dept. of Energy.

\section{References}

1. R.I. Karlsson, B.L. Josefson, "Three-D finite element analysis of temperatures and stresses in single-pass butt-welded pipe”, J. Pr. V. Tech., Vol. 112, Feb 1990, pp. 76-84. 2. J. Goldak, A. Oddy, M. Gu, W. Ma, A. Mashaie, E. Hughes, "Coupling heat transfer, microstructure evolution and thermal stress analysis in weld mechanics", IUTAM Symp., Lulea, Sweden, June 1991.

3. P. Tekriwal ,J. Mazumder, "Transient and residual thermal strain-stress analysis of GMAW”, J. Engr. Mat. \& Tech., Vol. 113, July 1991, pp. 336-343.

4. A.R. Ortega, L.A. Bertram, E.A. Fuchs, K.W. Mahin, D.V. Nelson, "Thermomechanical modeling of a stationary gas metal arc weld: A comparison between numerical and experimental results", Int'l Trends in Welding Science \& Technology, Ed. S.A. David and J.M. Vitek, ASM Int'l, 1992, pp. 89-93.

5. J.H. Root, T.M. Holden, J. Schroder, S, Spooner, C.A. Hubbard, T.A. Dodson, S.A. David, "Residual stresses in a multipass ferritic weldment", Int'l Trends in Welding Science \& Technology, Ed. S.A. David, J.M. Vitek, ASM Int'l, 1992, pp. 99-103.

6. D.J. Bammann, M.L. Chiesa, G.C. Johnson, "A state variable damage model for temperature and strain rate dependent metals", Constitutive laws: Theory, experiments and numerical implementation, eds. A.M. Rajendran, R.C. Batra, pub. CIMNE, . Barcelona, Spain, September, 1995.

7. P. Dong, J.K. Hong, P. Rogers, "Analysis of residual stresses in Al-Li repair welds and mitigation techniques", Weld. J., Nov 1998, pp. 439s-445s.

8. A.R. Ortega, J.J. Dike, J.F. Lathrop, C.H. Cadden, D.R. Folk, J.E. Robles, “Analysis and validation of multi-pass girth welds in pipes", Modeling of Casting, Welding and Adv. Solidification Proc. VII, Ed. B.G. Thomas, C. Beckermann, 1998, pp. 779-786.

9. C.L. Tsai, M.L. Liaw, J.I. Teng, "Effect of residual stresses on design assessment of partial penetration laser welds in a press. valve component", W. J., Oct 98, pp. 403s-410s. 10. D.K. Gartling, R.E. Hogan, M.W. Glass, "COYOTE-A finite element computer program for nonlinear heat conduction problems", SAND94-1179, Sandia N. Labs, 1999. 11. M.L. Blanford, "JAS3D - A multi-strategy iterative code for solid mechanics analysis", internal report, Sandia National Laboratories, 1998. 